\title{
BMJ Open Interest and preferences for using advanced physical activity tracking devices: results of a national cross-sectional survey
}

\author{
Stephanie Alley, ${ }^{1}$ Stephanie Schoeppe, ${ }^{1}$ Diana Guertler, ${ }^{2}$ Cally Jennings, ${ }^{3}$ \\ Mitch J Duncan, ${ }^{4}$ Corneel Vandelanotte ${ }^{1}$
}

To cite: Alley S, Schoeppe S, Guertler D, et al. Interest and preferences for using advanced physical activity tracking devices: results of a national cross-sectional survey. BMJ Open 2016;6: e011243. doi:10.1136/ bmjopen-2016-011243

- Prepublication history and additional material is available. To view please visit the journal (http://dx.doi.org/ 10.1136/bmjopen-2016011243).

Received 21 January 2016 Revised 9 May 2016 Accepted 11 May 2016

CrossMark

For numbered affiliations see end of article.

Correspondence to Dr Stephanie Alley; s.alley@cqu.edu.au

\section{ABSTRACT}

Objectives: Pedometers are an effective selfmonitoring tool to increase users' physical activity. However, a range of advanced trackers that measure physical activity 24 hours per day have emerged (eg, Fitbit). The current study aims to determine people's current use, interest and preferences for advanced trackers.

Design and participants: A cross-sectional national telephone survey was conducted in Australia with 1349 respondents.

Outcome measures: Regression analyses were used to determine whether tracker interest and use, and use of advanced trackers over pedometers is a function of demographics. Preferences for tracker features and reasons for not wanting to wear a tracker are also presented.

Results: Over one-third of participants (35\%) had used a tracker, and $16 \%$ are interested in using one. Multinomial regression $(n=1257)$ revealed that the use of trackers was lower in males $(\mathrm{OR}=0.48,95 \% \mathrm{Cl} 0.36$ to 0.65$)$, non-working participants $(\mathrm{OR}=0.43,95 \% \mathrm{Cl}$ 0.30 to 0.61 ), participants with lower education (OR=0.52, $95 \% \mathrm{Cl} 0.38$ to 0.72 ) and inactive participants ( $\mathrm{OR}=0.52,95 \% \mathrm{Cl} 0.39$ to 0.70 ). Interest in using a tracker was higher in younger participants (OR=1.73, $95 \% \mathrm{Cl} 1.15$ to 2.58 ). The most frequently used tracker was a pedometer (59\%). Logistic regression $(n=445)$ revealed that use of advanced trackers compared with pedometers was higher in males (OR=1.67, $95 \% \mathrm{Cl} 1.01$ to 2.79 ) and younger participants (OR=2.96, 95\% Cl 1.71 to 5.13$)$, and lower in inactive participants $(\mathrm{OR}=0.35,95 \% \mathrm{Cl} 0.19$ to 0.63 ). Over half of current or interested tracker users (53\%) prefer to wear it on their wrist, $31 \%$ considered counting steps the most important function and $30 \%$ regarded accuracy as the most important characteristic. The main reasons for not wanting to use a tracker were, 'I don't think it would help me' (39\%), and 'I don't want to increase my activity' (47\%).

Conclusions: Activity trackers are a promising tool to engage people in self-monitoring a physical activity. Trackers used in physical activity interventions should align with the preferences of

\section{Strengths and limitations of this study}

- Large representative sample of Australian adults.

- Findings useful to health promotion workers and researchers running physical activity programmes.

- The cross-sectional data do not allow us to determine causation.

- The self-report data may be subject to social desirability bias.

target groups, and should be able to be worn on the wrist, measure steps and be accurate.

\section{BACKGROUND}

More than $33 \%$ of the world's adult population, ${ }^{1}$ and more than half of all Australians are insufficiently active for health benefit. ${ }^{2}$ This level of inactivity is a public health concern as regular physical activity improves health and well-being, and significantly lowers the risk of non-communicable diseases, including cardiovascular disease, diabetes and cancer. ${ }^{3}$ Individuals who are physically active have a $30-50 \%$ lower risk for developing non-communicable diseases, and a 20-50\% lower risk of mortality than physically inactive individuals. ${ }^{4-6}$ Hence, interventions to increase physical activity are needed.

Personal physical activity trackers, which enable people to monitor their physical activity, include pedometers, accelerometers, smartphone applications and heart rate monitors. Pedometers apply the oldest technology to record impacts produced by steps, but are still used as they are simple, low cost and have a long battery life. Strong evidence indicates that pedometers are an effective way to increase physical activity. ${ }^{7} 8$ This could be due to the user's increased awareness of 
their physical activity, and because the tracker provides an easy and accurate method of self-monitoring. ${ }^{9} \quad 10$ Self-monitoring, where people measure their own physical activity to compare it to a standard or personal goal, has been found to be one of the most effective behaviour change techniques available. ${ }^{11}$ There is now a wide range of trackers available for personal use, with varying monitoring features, physical forms and characteristics. Monitoring features typically include measurement of steps, heart rate, calories and body movement. The trackers are usually attached to the wrist or belt, and have varying characteristics, including screens, battery life, waterproof cases and goal setting features. Some trackers also have advanced connectivity options to allow users to connect and compete with others via smartphone apps or websites.

A range of advanced electronic physical activity trackers (eg, Garmin, Fitbit, Jawbone) can measure activity 24 hours per day, provide real-time feedback on performance, and seamlessly synchronise with other wearable technology (eg, smartphone, tablet) to provide greater detail on physical activity behaviour. Many advanced trackers also monitor user's sleep and sedentary behaviour. ${ }^{12}{ }^{13}$ Smartphone applications that use the accelerometer built into the smartphone have also become available (eg, moves, myfitness pal), but require the user to keep their phone with them at all times, thus significantly reducing the battery life of the phone. ${ }^{14}$ Lastly, heart rate monitors are used to measure the user's heart rate during exercise for an accurate measure on intensity and energy expenditure. ${ }^{13}$

Although activity trackers are an effective motivational tool to help users increase their physical activity, additional support may promote long-term engagement with the tracker and support the users in maintaining an active lifestyle. ${ }^{15}$ Behavioural change interventions in conjunction with the activity trackers provide theorybased behaviour change techniques to support longterm activity changes after the initial excitement with the activity tracker wears off. In turn, activity trackers can improve participation and compliance with physical activity programmes by engaging participants in selfmonitoring their physical activity. ${ }^{16}{ }^{17}$ Pedometers have been successfully used in many physical activity programmes, ${ }^{7} 18 \quad 19$ but few programmes have used the newly available advanced electronic activity trackers. These trackers have the ability to automate several components of physical activity interventions, including reminders, self-monitoring and goal setting, which are associated with increased behaviour change and compliance. $^{2021}$ These are particularly suited to e-health and $m$-health interventions as the intervention websites and apps can be set up to automatically sync self-monitoring data from participants' trackers. Physical activity programmes may, therefore, be more effective when using the advanced technology of accelerometers.

Despite the potential for use of modern physical activity trackers for promoting physical activity, there is little knowledge about the interest, usage and preferences for using advanced trackers, smartphone applications and heart rate monitors as compared with pedometers. Furthermore, to the best of our knowledge, no studies have explored interest and use of these new physical activity trackers among different population groups. Interventions that accommodate their target audience's preferences for intervention components have demonstrated improved effectiveness compared with those that do not consider these factors. ${ }^{22}{ }^{23}$ Participants who are satisfied with an intervention are more likely to comply with the protocol and show positive behaviour changes. ${ }^{22}$ Further, compliance to accelerometer use has been found to vary by accelerometer characteristics, such as wear location, and participant's demographics, including gender and physical activity levels. ${ }^{24}$ Although these findings are for accelerometers measuring research outcomes rather than self-monitoring, they highlight the need to choose trackers suited to the target population in order to promote a high usage. Therefore, an understanding of the preferences for different activity trackers according to demographic subgroups is vital to successfully use tracking devices to engage people in monitoring physical activity. This study aimed to examine interest, usage and preferences of physical activity trackers in Australian adults, including differences by demographic factors and physical activity levels.

\section{METHODS}

\section{Population}

The 'National Social Survey (NSS)' is an annual crosssectional survey collected by the Population Research Laboratory at Central Queensland University (CQU), Australia. Data were collected between November and December 2014 using Computer-Assisted-TelephoneInterviewing (CATI). A sample of individuals was randomly selected from a database with Australian landline and mobile telephone numbers. Inclusion criteria were being 18 years old or more and residing in Australia during the project. Informed consent was given before the start of the interview.

\section{Measures}

Interest, use and preferences for activity trackers were measured by 10 questions. First, participants were asked if they thought activity trackers can help people get more active (strongly agree to strongly disagree on a five-point Likert scale). Tracker use was assessed by asking participants if they had ever used an activity tracker (yes/no). Participants who had used activity trackers were further asked what type of tracker they used (open ended), how often they used the tracker (never, only during exercise, only during waking hours, only at night, all day and all night), how long they had used the tracker $(<1$ month, longer than 12 months) and if their physical activity had increased while they were wearing the tracker (no increase, <1-hour increase per week, 1-2-hour increase, 
3-4-hour increase or more than 4-hour increase). Participants who had not used a physical activity tracker were asked if they would be interested in using a tracker (very interested-not interested at all on a five-point Likert scale). Participants who have used a tracker or answered neutral to very interested in using a tracker were subsequently asked how often they would be willing to wear an activity tracker (never, only during exercise, only during waking hours, only at night, all day and all night). This group was also asked to select their two most preferred locations to wear a tracker (wrist, ankle, upper arm, waist, clipped on bra or pocket), their two most preferred characteristics (automatic sync, waterproof, accuracy, long battery life, having a screen, able to set goals, connects to internet or smartphone application, comfort or well hidden) and their top two preferred functions (measurements of steps, body movement, heart rate, calories, sleep or distance travelled by foot or push bike). Finally, this group was asked how often they would want to receive notifications through their tracker about physical activity (every $30 \mathrm{~min}$ or less to never). Finally, participants who had not used a tracker and were not interested in using one were asked to provide a reason as to why. Participants could select from given response options (cost, technology, time, not helpful, don't need to get more active), or specify their own alternate reason (see supplementary file 1 for question list).

Physical activity was measured using the Active Australia Questionnaire. ${ }^{26}$ Total physical activity was calculated by summing the time spent in walking, moderate activity and vigorous activity (doubled) according to manual instructions. ${ }^{26}$ The Active Australia Questionnaire has demonstrated acceptable reliability (intraclass correlation coefficient $=0.64)^{26}$ and criterion validity $(r=0.61) .{ }^{27}$ In line with the Australian physical activity guidelines recommending that adults engage in at least $150 \mathrm{~min}$ of physical activity per week, ${ }^{28}$ participants were classified as inactive $(<150 \mathrm{~min})$ or active $(\geq 150 \mathrm{~min})$.

Body mass index (BMI) was calculated by dividing participants' self-reported weight by height squared $\left(\mathrm{kg} / \mathrm{m}^{2}\right)$. Following the Australian classifications for overweight and obesity ${ }^{29}$ participants were divided into three weight categories based on their BMI (normal: <25; overweight: $\geq 25$ to $<30$ and obese: $\geq 30$ ).

Chronic disease status participants were classified as having a chronic disease if they identified themselves as having a current diagnosis of heart disease, high blood pressure, stroke, cancer, depression/anxiety, diabetes, arthritis, chronic back pain, asthma, chronic obstructive pulmonary disease or kidney disease.

Sociodemographic factors included gender, age, education (no tertiary education, technical college and university) and employment (full time, part time or casual, and not employed). The not employed category includes respondents who are retired and who engage in full-time home duties. Based on the median age of the sample, participants were divided into two categories of younger ( $<55$ years) and older ( $\geq 55$ years).

\section{Statistical analysis}

Frequencies of participant attitudes towards effectiveness of tracker use and interest in using a tracker use are presented. A $\chi^{2}$ test was conducted to compare the belief of tracker effectiveness for participants who had and had not used a tracker. Multinomial logistic regression was performed to determine the associations of gender, age, employment, education, physical activity, BMI and chronic disease status with activity tracker use and interest. The length of tracker use, belief that tracker use increased physical activity and types of trackers used are presented for participants who have used or currently use a tracker. Logistic regression was performed to determine the associations of gender, age, employment, education, physical activity, BMI and chronic disease status with use of advanced trackers as compared with pedometers. The percentage of respondents who selected each location, function and characteristic option as their first and second preference is presented along with preferences for notification frequencies. Lastly, reasons for not wanting to use a tracker are presented for participants who do not use a tracker and are not interested in using one. The required sample size to detect significant differences in tracker usage with ORs $<0.7$ and $>1.4$, and significance level set at $\mathrm{p}<0.05$ and power at $80 \%$ is $\mathrm{n}=1196 .{ }^{30}$

\section{RESULTS}

The response rate for the 2014 NSS was $29 \%$, which is comparable to other telephone surveys. ${ }^{31}$ Data were collected from 1349 participants. The sample had a higher proportion of adults over 65 years of age $(31 \%)$ compared with the Australian adult population (22\%), and the percentage of males (49\%) was similar to the Australian population $(50 \%) .{ }^{32}$ The sample had a slightly higher percentage of people with a tertiary education $(64 \%)$, and a higher percentage of people not working (43\%) compared with the Australian population $(59 \%$ and $33 \%$, respectively). ${ }^{33}$

\section{Tracker interest and use}

Over a third of the sample $(35 \%)$ were using or have used an activity tracker, $16 \%$ were interested in using a tracker and $44 \%$ were not interested in using a tracker ( $5 \%$ don't know; table 1). Multinomial regression found that males, non-workers, those with lower education and inactive participants were significantly less likely to use or have used a tracker compared with their counterparts. Lastly young people were more likely to be interested in wearing a tracker compared with older participants (table 2).

More than half of the participants (63\%) believed that activity trackers help people become more active, $16 \%$ were neutral and $17 \%$ do not think trackers would help (5\% don't know). Of those who have used an activity tracker, $74 \%$ believe that trackers are helpful compared 
Table 1 Demographics of Australian adults by tracker use and interest

\begin{tabular}{|c|c|c|c|c|}
\hline & $\begin{array}{l}\text { Uses/d tracker } \\
n=468 \\
n(\%)\end{array}$ & $\begin{array}{l}\text { Interested } \\
\mathrm{n}=209 \\
\mathrm{n}(\%)\end{array}$ & $\begin{array}{l}\text { Not interested } \\
n=580 \\
n(\%)\end{array}$ & $\begin{array}{l}\text { Total } \\
N=1253 \\
n(\%)\end{array}$ \\
\hline \multicolumn{5}{|l|}{ Gender } \\
\hline Males & $192(41)$ & $102(49)$ & $322(56)$ & $616(49)$ \\
\hline Females & 275 (59) & $107(51)$ & $255(44)$ & $637(51)$ \\
\hline \multicolumn{5}{|l|}{ Age (years) } \\
\hline Under 55 & $257(55)$ & $127(61)$ & $230(40)$ & $614(49)$ \\
\hline Over 55 & $210(45)$ & $82(39)$ & $347(60)$ & $639(51)$ \\
\hline \multicolumn{5}{|l|}{ Employment } \\
\hline Not employed & $154(33)$ & $74(35)$ & $315(54)$ & $541(43)$ \\
\hline Part time & $105(23)$ & $49(23)$ & $80(14)$ & 234 (19) \\
\hline Full time & $208(44)$ & $86(41)$ & 184 (32) & 478 (38) \\
\hline \multicolumn{5}{|l|}{ Education } \\
\hline Less than tertiary & $127(27)$ & $72(34)$ & $250(43)$ & $449(36)$ \\
\hline Technical college & $91(20)$ & $52(25)$ & $125(22)$ & $268(21)$ \\
\hline University & 249 (53) & $85(41)$ & 202 (35) & $536(43)$ \\
\hline \multicolumn{5}{|l|}{ BMI } \\
\hline Obese & $122(26)$ & $65(31)$ & $145(25)$ & $332(27)$ \\
\hline Overweight & $164(35)$ & $63(30)$ & 222 (39) & 449 (36) \\
\hline Normal & $181(39)$ & $81(39)$ & $210(36)$ & $472(38)$ \\
\hline \multicolumn{5}{|l|}{ Physical activity } \\
\hline Inactive & $125(27)$ & $77(37)$ & $242(42)$ & $444(35)$ \\
\hline Active & $342(73)$ & $132(63)$ & $335(58)$ & $809(65)$ \\
\hline \multicolumn{5}{|l|}{ Chronic disease } \\
\hline No & $221(47)$ & $106(51)$ & $235(41)$ & $562(45)$ \\
\hline Yes & $246(53)$ & $103(49)$ & $342(59)$ & $691(55)$ \\
\hline
\end{tabular}

with $58 \%$ who have not used a tracker $\left(\chi^{2}=35.55\right.$, $\mathrm{p}<0.001)$.

Of participants who have used a tracker $(n=468), 37 \%$ used it for less than a month, $35 \%$ between 1 and 6 months, and $27 \%$ for more than 6 months. Just under half $(48 \%)$ thought the tracker helped them to get more active while $50 \%$ did not think it helped (don't know=2\%).

\section{Barriers to tracker use}

Of the participants who were not interested in using a physical activity tracker $(\mathrm{n}=575 ; 43 \%$ of total sample), the two most commonly reported reasons were that these people did not want to increase their physical activity (37\%) or do not think it would be helpful $(34 \%)$. The participants who gave the reason that they do not want to get more active were slightly more active $(\mathrm{M}=340, \mathrm{SD}=373)$ than the other participants $(\mathrm{M}=312$, $\mathrm{SD}=389)$, but this difference was not significant, $\mathrm{t}(1$, $616)=0.852, p=0.39$. Low percentages were observed for other reasons of why they were not interested in using a tracker: cost $(3 \%)$, technology $(3 \%)$, lack of time $(6 \%)$, being too old $(1 \%)$, health $(3 \%)$, no interest $(6 \%)$ or other $(6 \%)$.

\section{Tracker preferences}

Of the 468 participants who have used a tracker (35\% of the total sample), the most commonly used tracker was a pedometer $(58 \%)$ while advanced physical activity trackers, including heart rate monitors $(12 \%)$, accelerometers (eg, Fitbit; 11\%) and smart phone applications $(15 \%)$, were less widely used. Table 3 lists demographics of respondents who used an advanced tracker and respondents who used a pedometer. More males, and younger participants and inactive participants used advanced trackers compared with classic pedometers (table 4).

Of those who currently use a tracker $(n=468)$ are interested $(n=210)$ or neutral $(n=53)$ about using a tracker ( $55 \%$ of the total sample), $46 \%$ would want to receive a notification from their tracker once per day, $15 \%$ would prefer more than once per day and $21 \%$ less than once a day. This leaves $13 \%$ who would never like to receive a notification (don't know=5\%). Table 5 presents the scores for tracker options under the categories of location, functionality and characteristic in the same subsample $(n=731)$. Options are listed in each category from high to low frequency of first preference.

\section{DISCUSSION}

Past research has demonstrated the importance of selfmonitoring for behaviour change. ${ }^{11}$ The findings from the current study suggest that Australians have a high level of interest in activity trackers and these may, therefore, be a promising method to engage people in selfmonitoring their physical activity. In this sample, 
Table 2 Multinomial logistic regression for demographics by tracker use and interest

\begin{tabular}{|c|c|c|}
\hline & $\begin{array}{l}\text { Using a } \\
\text { tracker OR } \\
(95 \% \mathrm{Cl})\end{array}$ & $\begin{array}{l}\text { Interested to use } \\
\text { a tracker } \\
\text { OR }(95 \% \mathrm{Cl})\end{array}$ \\
\hline \multicolumn{3}{|l|}{ Gender } \\
\hline Males & $\begin{array}{l}0.48 \\
(0.36 \text { to } 0.65)^{\star * *}\end{array}$ & $\begin{array}{l}0.77 \\
(0.53 \text { to } 1.12)\end{array}$ \\
\hline Females & 1 & 1 \\
\hline \multicolumn{3}{|l|}{ Employment } \\
\hline Non-workers & $\begin{array}{l}0.43 \\
(0.30 \text { to } 0.61)^{\star * *}\end{array}$ & $\begin{array}{l}0.65 \\
(0.41 \text { to } 1.01)\end{array}$ \\
\hline Part time & $\begin{array}{l}0.93 \\
(0.62 \text { to } 1.39)\end{array}$ & $\begin{array}{l}1.24 \\
(0.76 \text { to } 2.05)\end{array}$ \\
\hline Full time & 1 & 1 \\
\hline \multicolumn{3}{|l|}{ Education } \\
\hline Less than tertiary & $\begin{array}{l}0.52 \\
(0.38 \text { to } 0.72)^{\star \star *}\end{array}$ & $\begin{array}{l}0.90 \\
(0.60 \text { to } 1.35)\end{array}$ \\
\hline Technical college & $\begin{array}{l}0.66 \\
(0.46 \text { to } 0.95)^{*}\end{array}$ & $\begin{array}{l}1.13 \\
(0.72 \text { to } 1.78)\end{array}$ \\
\hline University & 1 & 1 \\
\hline \multicolumn{3}{|l|}{$\mathrm{BMI}$} \\
\hline Obese & $\begin{array}{l}1.28 \\
(0.89 \text { to } 1.85)\end{array}$ & $\begin{array}{l}1.40 \\
(0.90 \text { to } 2.17)\end{array}$ \\
\hline Overweight & $\begin{array}{l}1.10 \\
(0.80 \text { to } 1.52)\end{array}$ & $\begin{array}{l}0.85 \\
(0.56 \text { to } 1.31)\end{array}$ \\
\hline Normal & 1 & 1 \\
\hline \multicolumn{3}{|l|}{ Age (years) } \\
\hline Under 55 & $\begin{array}{l}1.10 \\
(0.80 \text { to } 1.51)\end{array}$ & ${ }_{* *}^{1.73}(1.15$ to 2.58$)$ \\
\hline Over 55 & 1 & 1 \\
\hline \multicolumn{3}{|l|}{ Physical activity } \\
\hline Inactive & $\begin{array}{l}0.52 \\
(0.39 \text { to } 0.70)^{\star \star \star}\end{array}$ & $\begin{array}{l}0.81 \\
(0.56 \text { to } 1.16)\end{array}$ \\
\hline Active & 1 & 1 \\
\hline \multicolumn{3}{|l|}{ Chronic disease } \\
\hline No & $\begin{array}{l}0.91 \\
(0.68 \text { to } 1.24)\end{array}$ & $\begin{array}{l}1.12 \\
(0.76 \text { to } 1.63)\end{array}$ \\
\hline Yes & 1 & 1 \\
\hline
\end{tabular}

two-thirds of Australians believe that activity trackers help people get more active, and over $50 \%$ of Australians have used or are interested in using a physical activity tracker. It may be challenging to engage people who have not used a tracker and believe that these devices would not be helpful; however, it is promising that people who have used a tracker are more likely to think that trackers are helpful.

The majority $(72 \%)$ of respondents who had used a tracker used it for $<6$ months. This is in line with the findings from Kirwan $e t a l^{34}$ that people in a web-based physical activity programme, 10000 steps, logged steps through the intervention's application for an average of 62 days. Self-monitoring is important for the initiation and maintenance of physical activity habits. ${ }^{9}{ }^{10}$ However, it is not established how long one should engage in
Table 3 Demographics by tracker use type

\begin{tabular}{|c|c|c|c|}
\hline & $\begin{array}{l}\text { Advanced } \\
\text { trackers } \\
\mathrm{n}=267 \\
\mathrm{n}(\%)\end{array}$ & $\begin{array}{l}\text { Pedometer } \\
n=178 \\
n(\%)\end{array}$ & $\begin{array}{l}\text { Total } \\
\mathrm{N}=445 \\
\mathrm{n}(\%)\end{array}$ \\
\hline \multicolumn{4}{|l|}{ Gender } \\
\hline Males & $97(36)$ & $85(48)$ & $182(41)$ \\
\hline Females & $170(64)$ & $93(52)$ & 263 (59) \\
\hline \multicolumn{4}{|l|}{ Employment } \\
\hline Non-workers & $111(41)$ & 31 (17) & $142(32)$ \\
\hline Part time & $58(22)$ & $42(24)$ & $100(22)$ \\
\hline Full time & $98(37)$ & 105 (59) & $203(46)$ \\
\hline \multicolumn{4}{|l|}{ Education } \\
\hline $\begin{array}{l}\text { Less than } \\
\text { tertiary }\end{array}$ & $80(30)$ & $41(23)$ & $121(27)$ \\
\hline $\begin{array}{l}\text { Technical } \\
\text { college }\end{array}$ & $54(20)$ & $31(17)$ & $85(19)$ \\
\hline University & $133(50)$ & $106(60)$ & $239(54)$ \\
\hline \multicolumn{4}{|l|}{ BMI } \\
\hline Obese & $76(29)$ & $36(20)$ & $112(25)$ \\
\hline Overweight & $97(36)$ & $59(33)$ & $156(35)$ \\
\hline Normal & $94(35)$ & $83(47)$ & $177(40)$ \\
\hline \multicolumn{4}{|l|}{ Age (years) } \\
\hline Under 55 & $116(43)$ & $132(74)$ & $248(56)$ \\
\hline Over 55 & $151(57)$ & $46(26)$ & $197(44)$ \\
\hline \multicolumn{4}{|l|}{ Physical activity } \\
\hline Inactive & $91(34)$ & 25 (14) & $116(26)$ \\
\hline Active & $176(66)$ & $153(86)$ & $329(74)$ \\
\hline \multicolumn{4}{|l|}{ Chronic disease } \\
\hline No & $102(57)$ & $113(42)$ & $215(48)$ \\
\hline Yes & 76 (42) & $154(58)$ & $230(52)$ \\
\hline
\end{tabular}

self-monitoring to ensure the new habit has established itself. It is possible that over time participants learn how active they need to be to reach their daily goals without the use of an activity tracker. As such, ceasing to use an activity tracker does not necessarily mean they have stopped being active.

It is not surprising that inactive people, males, people with less education and non-workers were less likely to have used a tracker as they are usually the least interested in increasing their physical activity. ${ }^{35} 36$ This is in line with the findings from Eakin $e t a l^{37}$ that pedometer users were more likely to be female and have higher levels of education compared with those who have not used a pedometer. These findings indicate that we need to continue to look for other avenues to engage the population groups that are less likely to use activity trackers. Younger participants were significantly more interested in using a tracker, which is in contrast to the study by Eakin $e t a l^{7}$ who found that older participants were more likely to have used a tracker. This may be due to the new advanced trackers sparking the interest of younger people because this connects in with how they use new technology (smartphones, apps, social networking). ${ }^{38}$ This is an important finding as younger participants are typically harder to reach through physical 
Table 4 Logistic regression for demographics by tracker types

\begin{tabular}{|c|c|}
\hline & $\begin{array}{l}\text { Advanced trackers } \\
\text { OR (Cl) }\end{array}$ \\
\hline \multicolumn{2}{|l|}{ Gender } \\
\hline Males & $1.67(1.01 \text { to } 2.79)^{*}$ \\
\hline Females & 1 \\
\hline \multicolumn{2}{|l|}{ Employment } \\
\hline Non-workers & $0.52(0.27$ to 1.01$)$ \\
\hline Part time & 0.85 (0.46 to 1.56$)$ \\
\hline Full time & 1 \\
\hline \multicolumn{2}{|l|}{ Education } \\
\hline Less than tertiary & $0.87(0.49$ to 1.56$)$ \\
\hline Technical collage & $0.82(0.44$ to 1.56$)$ \\
\hline University & 1 \\
\hline \multicolumn{2}{|l|}{$\mathrm{BMI}$} \\
\hline Obese & $0.65(0.35$ to 1.21$)$ \\
\hline Overweight & 0.70 (0.40 to 1.22$)$ \\
\hline Normal & 1 \\
\hline \multicolumn{2}{|l|}{ Age (years) } \\
\hline Under 55 & $2.96(1.71 \text { to } 5.13)^{\star \star \star}$ \\
\hline Over 55 & 1 \\
\hline \multicolumn{2}{|l|}{ Physical activity } \\
\hline Inactive & $0.35(0.19 \text { to } 0.63)^{\star *}$ \\
\hline Active & 1 \\
\hline \multicolumn{2}{|l|}{ Chronic disease } \\
\hline No & $0.98(0.59$ to 1.64$)$ \\
\hline Yes & 1 \\
\hline $\begin{array}{l}\text { Reference: pedometer. } \\
{ }^{*} p<0.05,{ }^{* *} p<0.01,{ }^{* \star *} p \\
\text { BMI, body mass index. }\end{array}$ & \\
\hline
\end{tabular}

activity interventions. ${ }^{17}$ Use of advanced activity trackers may, therefore, be a new way of engaging this demographic, though randomised controlled trials will be needed to confirm this.

Pedometers were the most frequently used tracker. This may be so as pedometers have been available for a longer time, are low cost and are part of many ongoing physical activity programmes (eg, 10000 Steps). The use of advanced trackers (smart phone applications, accelerometers and heart rate monitors) over pedometers is higher in males, those who are physically active and younger. The higher use in active people may be explained by the additional functionality offered by the advanced trackers in relation to accurately measuring vigorous physical activity. The higher use of pedometers in the older age group may be due to older people preferring simple technology, ${ }^{38}$ as well as their lower participation in vigorous activity. ${ }^{2}$ The higher use in males may be as they are more interested in new technology (ie, gadgets) than women. ${ }^{39}$ These results are valuable for researchers and public health professionals aiming to promote physical activity to specific population subgroups, as it will help them to choose trackers suited to their target population. These patterns of use provide insight into which trackers will attract hard-to-reach demographics or particular intervention target audiences. For example, pedometers are more likely to engage older people while advanced trackers are more likely to engage males and younger participants.

The preferred location, function and characteristics of trackers (wrist, counting steps and accuracy, respectively) vary both between and within tracker categories. It is interesting to note that the respondent's most important function is counting steps which can be achieved by the simplest device, pedometers. This may be because the number of steps is a robust outcome that is easy to conceptualise, measure and interpret. ${ }^{7}$ However, this result could also have been influenced by the high number of pedometer users in the study sample. The second most popular function is measuring heart rate, which is increasingly common in the advanced trackers. The wrist was the most popular place to wear a tracker, which is the most common location when using advanced trackers. The most popular characteristic is accuracy which differs across brands in each tracker category. The second most popular characteristic is syncing to devices which is most common in accelerometers. As such, accelerometers (eg, Fitbit, Jawbone) may, therefore, be the best overall match with preferred characteristics, functions and location of the trackers. Researchers and public health professionals choosing trackers must

Table 5 Frequency of tracker options chosen as first and second preference

\begin{tabular}{|c|c|c|c|c|c|c|c|c|}
\hline \multicolumn{3}{|l|}{ Location } & \multicolumn{3}{|l|}{ Function } & \multicolumn{3}{|l|}{ Characteristics } \\
\hline & First (\%) & Second (\%) & & First (\%) & Second (\%) & & First (\%) & Second (\%) \\
\hline Wrist & 52 & 23 & Counting steps & 29 & 16 & Accuracy & 27 & 16 \\
\hline $\begin{array}{l}\text { Pocket or } \\
\text { handbag }\end{array}$ & 20 & 28 & $\begin{array}{l}\text { Measuring heart } \\
\text { rate }\end{array}$ & 23 & 22 & Sync to devices & 17 & 11 \\
\hline Waist & 15 & 11 & $\begin{array}{l}\text { Measuring body } \\
\text { movement }\end{array}$ & 18 & 13 & $\begin{array}{l}\text { Screen to view } \\
\text { activity }\end{array}$ & 17 & 14 \\
\hline Upper arm & 6 & 12 & Calories burnt & 13 & 21 & Comfort & 10 & 12 \\
\hline \multirow[t]{5}{*}{ Ankle } & 4 & 13 & Measuring sleep & 5 & 9 & Waterproof & 6 & 7 \\
\hline & & & Mapping travel & 4 & 5 & $\begin{array}{l}\text { Goal setting } \\
\text { features }\end{array}$ & 5 & 9 \\
\hline & & & & & & Long battery life & 5 & 9 \\
\hline & & & & & & Connectivity & 3 & 5 \\
\hline & & & & & & Well hidden & 1 & 3 \\
\hline
\end{tabular}


consider whether these are accurate, can be worn on the wrist and measure steps.

The majority of respondents who are interested in using a tracker said they would want to receive a notification updating them of their behaviour once a day, and of these, a small majority said they would like to receive notifications more than once a day. Preference for notification frequency may, however, differ by what behaviour the notification is about (reaching a goal, sedentary behaviour or physical activity). The overall preference for frequent notifications is promising as a notification once a day is enough for participants to remain aware of their physical activity and sedentary behaviour.9 1040 However, users are becoming accustomed to the ability to customise technology and software to suit their preferences and needs. Therefore, the more customisation we can include, the more satisfied the participants will be, and the more likely they will be engaged. ${ }^{41}$ Interventions may, therefore, consider choosing devices that give participants the ability to set their notification frequency.

Researchers and public health professionals considering using trackers to promote self-monitoring of physical activity should note that the technology and cost of trackers are not significant barriers to use in general. However, cost may be a barrier to using the more expensive tracker options (heart rate monitors or accelerometers). The most common reasons for not wanting to use an activity tracker are the beliefs that trackers are not effective and that they do not need to increase their physical activity. However, our study shows that the people who do not want to increase their activity are only slightly (not significantly) more active. Therefore, physical activity is probably not a priority for them, or they may think they are more active than they actually are. Vandelanotte $e t a l^{42}$ demonstrated that people tend to overestimate their physical activity levels. Activity trackers may be a useful tool for people to understand their true level of physical activity and realise that they need to become more active, but these might not motivate people who do not see the benefits from getting more active. Combining trackers with theory-based physical activity interventions may be optimal, as the trackers will aid with self-monitoring and increase the user's awareness of their activity, while the intervention content will provide the user with information and support to help and motivate them in becoming more active.

\section{Strengths and limitations}

The results demonstrate a high level of interest in activity trackers, and reveal the tracker types that will most likely engage participants. The data were collected through a cross-sectional self-report survey which may be subject to bias. The high percentage of the sample participants not working may have biased the findings. Findings should also be interpreted with caution given the older age of the sample. Use of advanced trackers may have been higher in a younger sample. Further, the availability and use of activity monitors is rapidly changing; therefore, the information collected is likely to continue to evolve. Pedometers have been found to improve the effectiveness of physical activity interventions; however, further research is needed to test the effectiveness of the advanced tracker, in particular the accelerometers which are the most in line with participants' preferences. Further research is needed to measure user interaction with activity monitors. Such findings will further aid public health professionals and researchers in choosing activity monitors which will engage participants in monitoring their physical activity. Lastly, future research is needed to investigate the relationship between psychosocial correlates of physical activity and interest in activity trackers. Some research has suggested that readiness to change physical activity is associated with interest in using an activity tracker. ${ }^{43}$ Further investigations would allow public health professionals and researchers to factor in psychosocial correlates of physical activity when choosing activity trackers to incorporate into physical activity interventions.

\section{CONCLUSIONS}

The high level of interest in activity trackers suggests these are a promising tool to engage people in selfmonitoring. Younger people, females, full-time workers, university graduates and more active people are more likely to use a tracker or be interested in using one overall. Public health professionals and researchers should choose which tracker to use based on the characteristics of their target audience. Findings suggest that older people are more likely to use pedometers, while advanced trackers are more likely to attract younger participants and males. Further, accelerometers (eg, Fitbit) align best with the preferred location (ie, wrist), features (ie, measures steps) and characteristics (ie, accuracy) of the overall sample. As satisfaction is important for compliance and engagement with trackers, ${ }^{24} 25$ these preferences should be considered when using trackers to promote physical activity. Population-based interventions may also want to provide participants the option of choosing their tracker so as to satisfy people with different demographic profiles with a single intervention.

\section{Author affiliations}

${ }^{1}$ Physical Activity Research Group, School of Human, Health and Social

Sciences, Central Queensland University, Rockhampton, Queensland, Australia

${ }^{2}$ Institute of Social Medicine and Prevention, University of Greifswald,

Greifswald, Germany

${ }^{3}$ Faculty of Physical Education and Recreation, University of Alberta, Edmonton, Alberta, Canada

${ }^{4}$ Faculty of Health and Medicine, School of Medicine \& Public Health; Priority

Research Centre for Physical Activity and Nutrition, The University of Newcastle, Callaghan, New South Wales, Australia

\section{Twitter Follow Mitch Duncan at @mitchjduncan}

Contributors SA set up survey questions and wrote the manuscript; SS, DG, MJD and CV assisted in setting up survey questions and reviewed the manuscript; CJ conceived the study and reviewed the manuscript. All authors read and approved the final manuscript. 
Funding Data collection through the National Social Survey was funded by a grant from the Population Research Laboratory, CQUniversity. CV is supported through a Future Leader Fellowship from the National Heart Foundation of Australia (100427), and MJD is supported by a Future Leader Fellowship (100029) from the National Heart Foundation of Australia.

\section{Patient consent Obtained.}

Ethics approval The survey was approved by the Central Queensland University Human Research Ethics Committee (H14/09-203).

Provenance and peer review Not commissioned; externally peer reviewed.

Data sharing statement No additional data are available.

Open Access This is an Open Access article distributed in accordance with the Creative Commons Attribution Non Commercial (CC BY-NC 4.0) license which permits others to distribute, remix, adapt, build upon this work noncommercially, and license their derivative works on different terms, provided the original work is properly cited and the use is non-commercial. See: http:// creativecommons.org/licenses/by-nc/4.0/

\section{REFERENCES}

1. World Health Organisation. Physical inactivity: a global public health problem. WHO, 2008.

2. Australian Bureau of Statistics. Australian Health Survey: first results, 2011-12 No. 4364.0.55.004.2013. Canberra, Australia: ABS 2013.

3. Lee IM, Shiroma EJ, Lobelo F, et al. Effect of physical inactivity on major non-communicable diseases worldwide: an analysis of burden of disease and life expectancy. Lancet 2012;380:219-29.

4. Bassuk SS, Manson JE. Epidemiological evidence for the role of physical activity in reducing risk of type 2 diabetes and cardiovascular disease. J Appl Physiol 2005;99:1193-204.

5. Friedenreich CM, Orenstein MR. Physical activity and cance prevention: etiologic evidence and biological mechanisms. J Nutr 2002;132:3456-64.

6. Warburton DE, Nicol CW, Bredin SS. Health benefits of physical activity: the evidence. CMAJ 2006;174:801-9.

7. Bravata DM, Smith-Spangler C, Sundaram V, et al. Using pedometers to increase physical activity and improve health: a systematic review. JAMA 2007;298:2296-304

8. Greaves CJ, Sheppard KE, Abraham C et al. Systematic review of reviews of intervention components associated with increased effectiveness in dietary and physical activity interventions. BMC Public Health 2011;11:119.

9. Conroy MB, Yang K, Elci OU, et al. Physical activity self-monitoring and weight loss: 6-month results of the SMART trial. Med Sci Sports Exerc 2011;43:1568-74.

10. Ferrier S, Blanchard CM, Vallis M, et al. Behavioural interventions to increase the physical activity of cardiac patients: a review. Eur $J$ Cardiovasc Prev Rehabil 2011;18:15-32.

11. Michie S, Abraham C, Whittington C, et al. Effective techniques in healthy eating and physical activity interventions: a meta-regression. Health Psychol 2009;28:690-701.

12. Yang CC, Hsu YL. A review of accelerometry-based wearable motion detectors for physical activity monitoring. Sensors (Basel) 2010;10:7772-88.

13. Andre D, Wolf DL. Recent advances in free-living physical activity monitoring: a review. J Diabetes Sci Technol 2007;1:760-7.

14. Intille SS, Lester J, Sallis JF, et al. New horizons in sensor development. Med Sci Sports Exerc 2012;44(Suppl 1):S24-31.

15. Bassett DR. Device-based monitoring in physical activity and public health research. Physiol Meas 2012;33:1769.

16. Bock C, Jarczok MN, Litaker D. Community-based efforts to promote physical activity: a systematic review of interventions considering mode of delivery, study quality and population subgroups. J Sci Med Sport 2014;17:276-82.

17. Davies C, Spence JC, Vandelanotte C, et al. Meta-analysis of internet-delivered interventions to increase physical activity levels. Int J Behav Nutr Phys Act 2012;9:52.

18. Walker S. Wearable technology-market assessment. IHS Electronics \& Media, 2013.
19. De Greef KP, Deforche BI, Ruige JB, et al. The effects of a pedometer-based behavioral modification program with telephone support on physical activity and sedentary behavior in type 2 diabetes patients. Patient Educ Couns 2011;84:275-9.

20. Greaney ML, Sprunck-Harrild K, Bennett GG, et al. Use of email and telephone prompts to increase self-monitoring in a web-based intervention: randomized controlled trial. J Med Internet Res 2012;14:e96.

21. Glasgow RE, Nelson CC, Kearney KA, et al. Reach, engagement, and retention in an internet-based weight loss program in a multi-site randomized controlled trial. J Med Internet Res 2007;9: e11.

22. King M, Nazareth I, Lampe F, et al. Impact of participant and physician intervention preferences on randomized trials: a systematic review. JAMA 2005;293:1089-99.

23. Short CE, Vandelanotte C, Duncan MJ. Individual characteristics associated with physical activity intervention delivery mode preferences among adults. Int J Behav Nutr Phys Act 2014;11:25

24. Hassani M, Kivimaki M, Elbaz A, et al. Non-consent to a wrist-worn accelerometer in older adults: the role of socio-demographic, behavioural and health factors. PLOS ONE 2014;9:e110816.

25. Fairclough SJ, Noonan R, Rowlands AV, et al. Wear compliance and activity in children wearing wrist- and hip-mounted accelerometers. Med Sci Sports Exerc 2016;48:245-53.

26. Australian Institute of Health and Welfare. The active Australia survey. A guide for manual implementation, analysis and reporting. Canberra, Australia: AlHW, 2003.

27. Fjeldsoe BS, Winkler EA, Marshall AL, et al. Active adults recall thei physical activity differently to less active adults: test-retest reliability and validity of a physical activity survey. Health Promot $J$ Austr 2013;24:26-31

28. Department of Health and Aging. National physical activity guidelines. Canberra, Australia: Australian Government, 2014.

29. Aging DoHa. About overweight and obesity. Canberra, Australia: DoHa, 2009.

30. Hsieh FY. Sample size tables for logistic regression. Stat Med 1989;8:795-802.

31. Curtin R, Presser S, Singer E. Changes in telephone survey non-response over the past quarter century. Public Opinion Quartlery 2005;69:87-98.

32. Australian Bureau of Statistics. Population by age and sex, regions of Australia, 2014 No. 3235.0.2015. Canberra, Australia: ABS. 2015.

33. Australian Bureau of Statistics. Education and work, Australia, May 2015 No. 6227.0.2015. Canberra, Australia: ABS. 2015

34. Kirwan M, Duncan MJ, Vandelanotte C, et al. Using smartphone technology to monitor physical activity in the 10,000 Steps program: a matched case-control trial. J Med Internet Res 2012;14:e55.

35. Wanberg CR. The individual experience of unemployment. Annu Rev Psychol 2012;63:369-96.

36. Caperchione CM, Vandelanotte C, Kolt GS, et al. What a man wants: understanding the challenges and motivations to physical activity participation and healthy eating in middle-aged Australian men. Am J Mens Health 2012;6:453-61.

37. Eakin EG, Mummery K, Reeves MM, et al. Correlates of pedometer use: results from a community-based physical activity intervention trial (10,000 Steps Rockhampton). Int J Behav Nutr Phys Act 2007;4:31

38. Australian Communications and Media Authority. Australians embrace a digital life. Canberra, Australia: ACMA, 2015.

39. Australian Communications and Media Authority. Australia in the digital economy 2009. Canberra, ACMA. 2009.

40. Butryn ML, Phelan S, Hill JO, et al. Consistent self-monitoring of weight: a key component of successful weight loss maintenance. Obesity (Silver Spring) 2007;15:3091-6.

41. Franke N, Piller FT. Key research issues in user interaction with use toolkits in a mass customisation system. Int $J$ Technol Manag 2003;26:578.

42. Vandelanotte C, Duncan MJ, Hanley C, et al. Identifying population subgroups at risk for underestimating weight health risks and overestimating physical activity health benefits. $J$ Health Psychol 2011;16:760-9.

43. Gouveia R, Karapanos E, Hassenzahl M. How do we engage with activity trackers? UbiComp '15; September 07-11; Osaka, Japan 2015. pp. 1305-16. doi:10.1145/2750858.2804290 